\title{
A Predictive Microsimulation Model to Estimate the Clinical Relevance of Reducing Alcohol Consumption in Alcohol Dependence
}

\author{
Clément François ${ }^{a} \quad$ Philippe Laramée ${ }^{a, b} \quad$ Nora Rahhali ${ }^{a}$ Ylana Chalem $^{a}$ \\ Samuel Aballéa ${ }^{c}$ Aurélie Millier ${ }^{c}$ Sébastien Bineau ${ }^{a}$ Mondher Toumi $^{b}$ \\ Jürgen Rehm ${ }^{d-f}$ \\ ${ }^{a}$ Lundbeck SAS, Issy-les-Moulineaux, ${ }^{b}$ Université Claude Bernard Lyon I, Villeurbanne, and ${ }^{\mathrm{C} C r e a t i v-C e u t i c a l, ~ P a r i s, ~}$ \\ France; ${ }^{d}$ Social and Epidemiological Research Department, Centre for Addiction and Mental Health, and ${ }^{\mathrm{e}}$ Dalla Lana \\ School of Public Health, University of Toronto, Toronto, Canada; ${ }^{\mathrm{f} K l i n i s c h e ~ P s y c h o l o g i e ~ u n d ~ P s y c h o t h e r a p i e, ~}$ \\ TU Dresden, Dresden, Germany
}

\section{Key Words}

Alcohol dependence · Microsimulation model · Nalmefene

\begin{abstract}
Background: Alcohol consumption is one of the most important factors for disease and disability in Europe. In clinical trials, nalmefene has resulted in a significant reduction in the number of heavy-drinking days (HDDs) per month and total alcohol consumption (TAC) among alcohol-dependent patients versus placebo. Methods: A microsimulation model was developed to estimate alcohol-attributable diseases and injuries in patients with alcohol dependence and to explore the clinical relevance of reducing alcohol consumption. Results: For all diseases and injuries considered, the number of events (inpatient episodes) increased with the number of HDDs and TAC per year. The model predicted that a reduction of $20 \mathrm{HDDs}$ per year would result in $941 \mathrm{fewer}$ alcohol-attributable events per 100,000 patients, while a reduction in intake of 3,000 g/year of pure alcohol (ethanol) would result in 1,325 fewer events per 100,000 patients. Conclusion: The potential gains of reducing consumption in alcohol-dependent patients were considerable.
\end{abstract}

(c) 2014 S. Karger AG, Basel

\begin{tabular}{ll}
\hline KARGER & $\begin{array}{l}\text { ( ) 2014 S. Karger AG, Basel } \\
\text { 1022-6877/14/0206-0269\$39.50/0 Open caccess }\end{array}$ \\
$\begin{array}{l}\text { E-Mail karger@karger.com } \\
\text { www.karger.com/ear }\end{array}$ & $\begin{array}{l}\text { This is an Open Access article licensed under the terms of the } \\
\text { Creative Commons Attribution-NonCommercial 3.0 Un- } \\
\text { ported license (CC BY-NC) (www.karger.com/OA-license), } \\
\text { applicable to the online version of the article only. Distribu- } \\
\text { tion permitted for non-commercial purposes only. }\end{array}$
\end{tabular}

\section{Introduction}

Alcohol dependence (AD) is a clinical disorder characterised by a cluster of physiological, psychological, behavioural and cognitive phenomena in which alcohol consumption takes on a much higher priority for an individual than other behaviours and obligations $[1,2]$. Formally diagnosed by the Diagnostic and Statistical Manual of Mental Disorders (DSM-IV) and/or the World Health Organisation's (WHO) International Classification of Diseases (ICD-10) $[3,4], \mathrm{AD}$ is one of the most common disorders of the central nervous system in the European Union (EU), with an estimated annual prevalence of between 3 and $4 \%[5,6]$. The high prevalence of $\mathrm{AD}$ corresponds to the high level of alcohol consumption in this region; the $\mathrm{EU}$ is the heaviest drinking region in the world and had an estimated adult per capita consumption level of 12.41 in 2009, which was more than twice the global average [7].

Data sharing statement: the relevant anonymised, patient-level data for the ESENSE1 and ESENSE2 studies, sample drinking pattern trajectories for patients during the simulation period and the model report submitted to the EMA are available from the authors. 
$\mathrm{AD}$ has adverse consequences for both individual health and for society [8]. The risk of alcohol-related mortality has been shown to increase almost exponentially as alcohol consumption increases, both for lifetime risk and absolute annual risk, with the absolute annual risk for chronic disease mortality almost doubling as alcohol consumption increases from 10 to $100 \mathrm{~g} /$ day [9]. Therefore, for people with $\mathrm{AD}$ with a high level of consumption, the mortality risks are manifold compared to abstainers, low- or moderate-level drinkers [10]. Alcohol use is also one of the greatest risk factors in Europe for disease and disability, with causal relationships existing between alcohol consumption and more than 200 types of disease and injury [11-13]. The risk of developing alcohol-attributable diseases and injuries increases with higher levels of alcohol consumption in a dose-dependent manner, while the pattern in which alcohol is consumed in terms of the frequency of heavy-drinking days (HDDs) also contributes to individual risk [14-16]. The risks of many negative social consequences of alcohol (such as physical violence and dysfunctional marriage, home life, working life and social life) also increase, often exponentially, with the amount of alcohol consumed [17].

The adverse consequences of alcohol consumption place a major economic strain on the individual and society [18-21]. One recent report estimated alcohol-related costs in the EU to be EUR 155.8 billion in 2010; this estimate included both the direct and indirect costs of alcohol consumption, encompassing the healthcare costs of alcohol-related diseases and injuries, judicial costs, and costs associated with the loss of productivity from unemployment, absenteeism and premature retirement or mortality [16]. AD is estimated to account for approximately $60 \%$ of total alcohol-related costs [22], although it is likely that this is an underestimate due to the majority of alcohol-dependent patients being undiagnosed [16].

Given the relationship between alcohol consumption and the risks of alcohol-attributable mortality, disease and injury, it is likely that reducing total alcohol consumption (TAC) and the number of HDDs would lead to a reduction in the alcohol-attributable health burden [16]. While traditional management regimes for $\mathrm{AD}$ have tended to focus on promoting abstinence through interventions such as cognitive behavioural therapy and pharmacotherapy, the more recent and alternative 'harm reduction approach' attempts to help patients achieve a reduction in consumption without the need to abstain from alcohol entirely. The latter approach is now widely recog- nised as a valid treatment goal for alcohol-dependent patients, with reductions in TAC and the number of HDDs being recognised by the European Medicines Agency (EMA) as two primary endpoints relevant for assessing the success of interventions designed to enable this treatment approach [19].

The European Commission recently granted marketing authorisation for nalmefene for the reduction of alcohol consumption in adult patients with $\mathrm{AD}$ who have a high drinking risk level (DRL) according to the WHO ( $>60 \mathrm{~g} /$ day of pure alcohol for men, $>40 \mathrm{~g} /$ day for women) without physical withdrawal symptoms, and who do not require immediate detoxification $[19,20]$. Nalmefene should only be prescribed in conjunction with continuous psychosocial support focused on treatment adherence and reducing alcohol consumption, and it should only be initiated in patients who continue to have a high DRL 2 weeks after their initial assessment [23]. Nalmefene has demonstrated efficacy in reducing both TAC and the number of HDDs per month in alcohol-dependent patients in three phase III clinical trials: ESENSE1 (NCT00811720), ESENSE2 (NCT00812461) and SENSE (NCT00811941) [24-28]. However, the clinical trials were not designed to demonstrate the impact of nalmefene on the incidence of alcohol-attributable diseases and injuries.

Evidence exists in the literature from a large number of time-series analyses and natural experiments that reductions in alcohol consumption lead to reduced mortality on a population level $[10,29-33]$. These natural experiments include analyses of the effects of prohibition or other political measures to reduce population alcohol consumption, such as taxation increases, on population mortality rates. Inevitably, many such studies are correlational only. Scenario modelling is an original approach that has recently been used to ascertain the positive effects of strategies to reduce alcohol consumption on mortality. For instance, in one analysis the consequences of providing pharmacotherapy to $40 \%$ of alcohol-dependent patients in the EU were predicted to lead to a reduction of 11,740 deaths in the first year $[16,34]$.

The aim of the current analysis is to develop a predictive microsimulation model to estimate the risks of alcohol-attributable diseases and injuries occurring at different alcohol consumption levels. The model can then be used to evaluate the clinical relevance of reducing alcohol consumption in terms of the number of alcohol-attributable diseases or injuries avoided. While previous work in this area has tended to investigate the health of general populations in relation to alcohol con- 
sumption $[16,35]$, this model focuses on alcohol consumption specifically in alcohol-dependent individuals, with the risk of various alcohol-attributable diseases and injuries modelled for each individual based on their simulated alcohol consumption. A microsimulation approach enables more accurate modelling of individual variation in patient characteristics and has been used for modelling a number of diseases, such as cancer and obesity [36-38]. During the EMA marketing authorisation process for nalmefene, this model was presented to the Committee for Medicinal Products for Human Use (CHMP) to demonstrate the clinical relevance of reduction of alcohol consumption with the use of the medicine [39].

\section{Methods}

\section{Model Overview}

A predictive microsimulation model using England as the reference case simulated the alcohol consumption of individual patients, day by day for 12 months, using statistical equations estimated from nalmefene clinical trial data on alcohol consumption in patients from 19 European countries. No treatment effect of nalmefene was considered in the model as data on alcohol consumption from clinical trials were taken from the month prior to baseline assessment when patients were screened before commencing treatment. The model used English hospitalisation data to derive the incidence of alcohol-attributable diseases and injuries in the general population. The relative risks of such clinical events for each patient in the model, based on their simulated alcohol consumption and the incidence of events in the general population, were derived from published international epidemiological studies measuring the association between level of alcohol consumption and the risk of alcohol-attributable injuries or diseases $[11,40-51]$. A summary of the main inputs to the microsimulation model is shown in figure 1.

The model outcomes ('events') were inpatient consultation episodes for a specific alcohol-attributable disease or injury (fig. 1). Probabilities of clinical events occurring were compared between categories of patients defined according to the number of modelled HDDs and TAC over the 12-month simulation period. An HDD was defined as a day with consumption of $60 \mathrm{~g}$ of pure alcohol or more for men and $40 \mathrm{~g}$ or more for women, in line with WHO criteria for high and very high DRLs $[19,20]$. TAC was equal to the sum of the number of grams of pure alcohol consumed per patient per day over the course of 1 year. The number of HDDs across 1 year was divided into eight categories with a range of $20 \mathrm{HDDs}$ per year, representing a difference of approximately two HDDs per month between successive HDD categories. TAC per year was divided into 14 categories with a difference of 3,000 g per year between each successive category, in order to represent a difference between successive categories of approximately $10 \mathrm{~g} / \mathrm{day}$.

The model was programmed in Scilab version 5.3.3 [52]. Results are presented per 100,000 patients per drinking category, and have been adjusted for the proportion of males and females in the

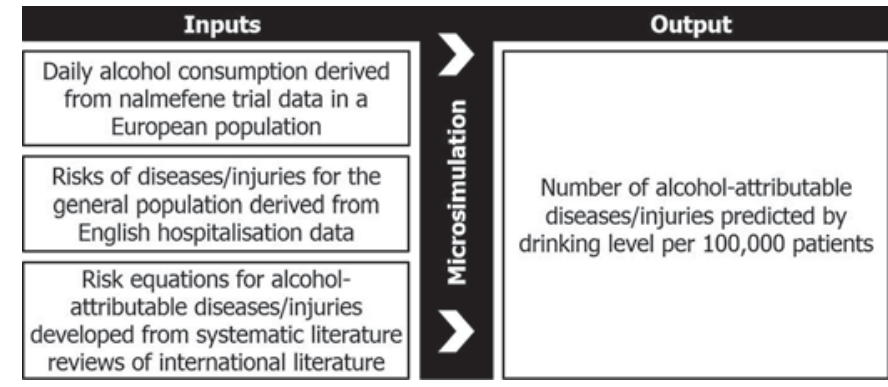

Fig. 1. Main inputs to and output from the microsimulation model.

clinical trials (68.6 and 31.4\%, respectively). To provide some context for the clinical relevance of reductions in alcohol consumption, the model results were considered in light of results from the three nalmefene phase III clinical trials for the licensed population.

\section{Simulating Alcohol Consumption}

A two-part statistical model based on two generalised linear mixed models (GLMMs) was constructed to predict alcohol consumption each day $[53,54]$. The first part was a logistic model predicting the probability of drinking any alcohol over 1 day as a function of patient characteristics and other factors identified as influencing alcohol consumption. Factors identified as influencing alcohol consumption included age, gender, day of the week, country and treatment history. In addition, alcohol consumption on a given day was found to be influenced by alcohol consumption during previous days, with log-transformed values of alcohol consumption the day before, 2 and 7 days before being significant predictors. The specific form of the logistic model for the reference case is given in equation 1, while the general version is presented in equation 2. Equation 1 uses an intercept estimate generated by the model, which is the coefficient from which the probability of drinking can be derived. In equation 2, a linear combination is used based on any deviations from the reference case in the factors identified as influencing alcohol consumption. An illustrative example demonstrating the use of this equation is provided in the footnote of table 1.

$$
p_{0}=\frac{e^{\text {Intercept }}}{1+e^{\text {Intercept }}},
$$

where $p_{0}$ is the probability of consuming alcohol on a reference patient day (male patient, in England, not previously treated, not included in the SENSE trial, on a Saturday and with all continuous factors equal to 0), and Intercept is a coefficient included in the model to represent the reference case.

$$
p=\frac{e^{\text {Linear Combination }}}{1+e^{\text {Linear Combination }}},
$$

where $p$ is the probability of consuming alcohol for cases other than the reference case and Linear Combination is a coefficient included in the model to represent the influences of various patient and other characteristics on the probability of consuming alcohol. The linear combination corresponds to the following formula: 
Table 1. Coefficients of logistic model for probability of drinking

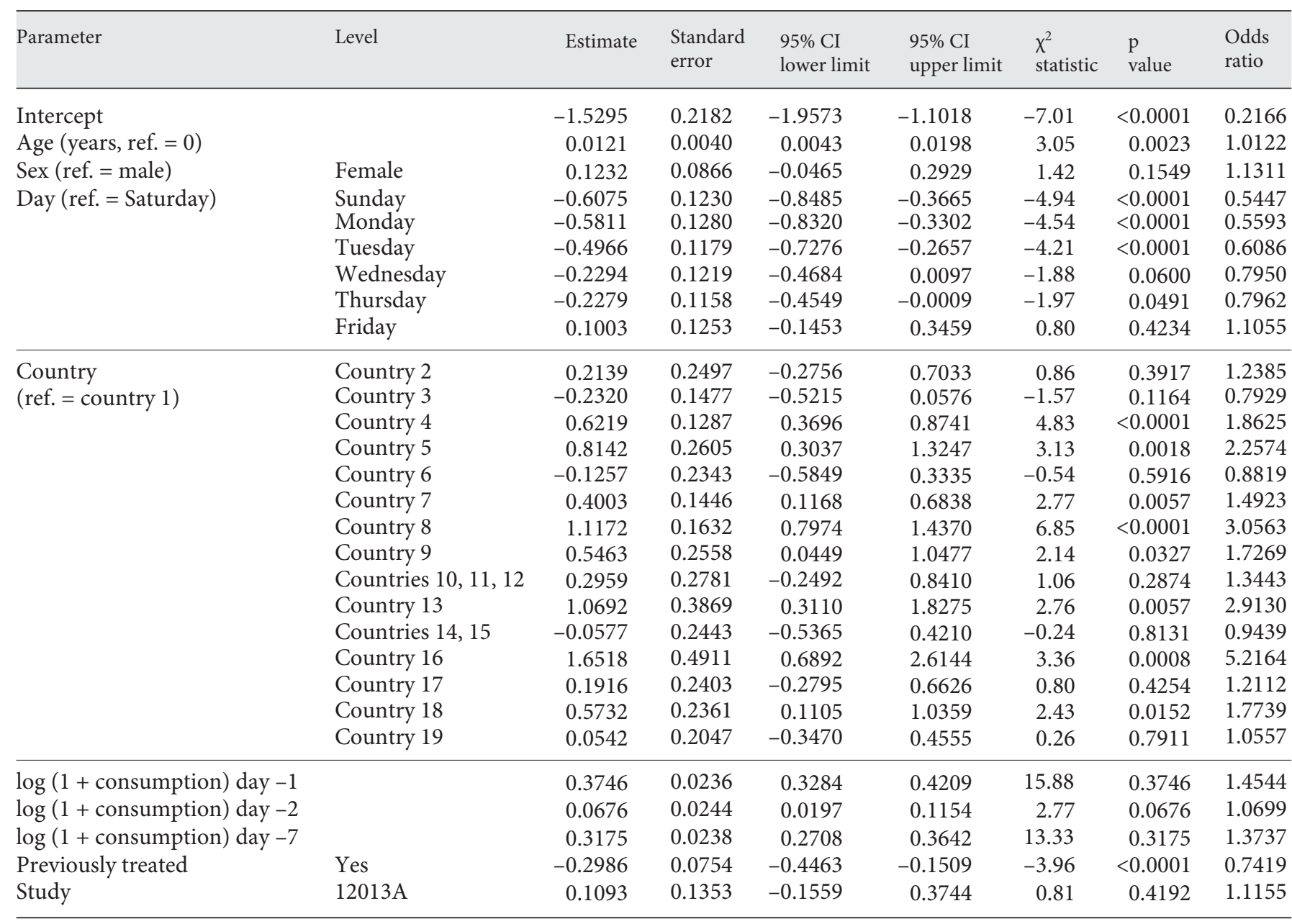

Illustrative example: assuming a female patient, aged 40, from country 1, previously treated, who drank $60 \mathrm{~g}$ of alcohol the day before, 2 and 7 days before, the probability of drinking on a Wednesday is calculated as:

$$
p=\frac{e^{-1.5295+40 \times 0.0121+0.1232-0.2294+\ln (1+60) \times 0.3746+\ln (1+60) \times 0.0676+\ln (1+60) \times 0.3175-0.2986}}{1+e^{-1.5295+40 \times 0.0121+0.1232-0.2294+\ln (1+60) \times 0.3746+\ln (1+60) \times 0.0676+\ln (1+60) \times 0.3175-0.2986}}=84.2 \% .
$$

$\beta_{0}+\beta_{1} x_{1}+\ldots+\beta_{m} x_{m}$, where $\beta_{i}$ is the $i$-th parameter in the logistic model, $x_{i}$ is the corresponding $i$-th patient characteristic, $\beta_{0}$ is the intercept, and $m$ the total number of parameters used in the model.

The second GLMM modelled the quantity of alcohol in grams consumed per day as a function of patient characteristics and other factors, including previous consumption, given that the patient drinks any alcohol that day. Several distribution functions were tested using the Akaike information criterion as quality of fit criteria [55]. It was found that the quantity of alcohol consumed in grams was best fitted to a negative binomial distribution $N B(r, p)$, where $r$ was the number of successes achieved (alcohol not consumed) and $p$ was the probability of a success. Similarly to the logarithmic equations, a linear combination was included in the negative binomial GLMM from which the mean amount of alcohol consumed could be derived. This linear equation took into account the influence of patient characteristics and drinking behaviour on the mean amount of alcohol consumed on a given day (equation 3).

$$
\mu=e^{\text {Linear Combination, }}
$$

where $\mu$ is the mean amount of alcohol consumed and Linear Combination is a coefficient included in the model to represent the influences of various patient and other characteristics on the mean amount of alcohol consumed. The linear combination corresponds to the following formula: $\beta_{0}+\beta_{1} x_{1}+\ldots+\beta_{m} x_{m}$, where $\beta_{i}$ is the $i$-th parameter in the negative binomial model and $x_{i}$ is the corresponding $i$-th patient characteristic, $\beta_{0}$ is the intercept and $m$ 
Table 2. Coefficients of negative binomial model for amount of alcohol consumed on drinking days

\begin{tabular}{|c|c|c|c|c|c|c|c|c|}
\hline Parameter & Level & Estimate & $\begin{array}{l}\text { Standard } \\
\text { error }\end{array}$ & $\begin{array}{l}95 \% \text { CI } \\
\text { lower limit }\end{array}$ & $\begin{array}{l}\text { 95\% CI } \\
\text { upper limit }\end{array}$ & $\begin{array}{l}\chi^{2} \\
\text { statistic }\end{array}$ & $\begin{array}{l}\mathrm{p} \\
\text { value }\end{array}$ & $\begin{array}{l}\text { Expected } \\
\text { estimate ratio }\end{array}$ \\
\hline Intercept & & 4.9365 & 0.1043 & 4.7320 & 5.1410 & 47.32 & $<0.0001$ & 139.2819 \\
\hline Sex $($ ref. $=$ male $)$ & Female & -0.2298 & 0.0324 & -0.2934 & -0.1663 & -7.09 & $<0.0001$ & 0.7947 \\
\hline \multirow[t]{4}{*}{ Day (ref. = Saturday) } & Sunday & -0.0885 & 0.0137 & -0.1154 & -0.0617 & -6.46 & $<0.0001$ & 0.9153 \\
\hline & Monday & -0.1922 & 0.0174 & -0.2262 & -0.1581 & -11.06 & $<0.0001$ & 0.8251 \\
\hline & Thursday & -0.1847 & 0.0167 & -0.2175 & -0.1519 & -11.04 & $<0.0001$ & 0.8314 \\
\hline & Friday & -0.0391 & 0.0132 & -0.0649 & -0.0132 & -2.96 & 0.0031 & 0.9617 \\
\hline Country & Country 2 & 0.0293 & 0.1108 & -0.1879 & 0.2466 & 0.26 & 0.7912 & 1.0297 \\
\hline \multirow[t]{10}{*}{$($ ref. $=$ country 1$)$} & Country 3 & -0.0918 & 0.0903 & -0.2688 & 0.0853 & -1.02 & 0.3098 & 0.9123 \\
\hline & Country 4 & -0.1645 & 0.0584 & -0.2789 & -0.0501 & -2.82 & 0.0048 & 0.8483 \\
\hline & Country 9 & -0.2389 & 0.1020 & -0.4388 & -0.0390 & -2.34 & 0.0192 & 0.7875 \\
\hline & Countries 10, 11, 12 & -0.1781 & 0.1211 & -0.4156 & 0.0593 & -1.47 & 0.1414 & 0.8369 \\
\hline & Country 13 & -0.1117 & 0.1064 & -0.3201 & 0.0968 & -1.05 & 0.2939 & 0.8943 \\
\hline & Countries 14,15 & -0.1726 & 0.1242 & -0.4159 & 0.0708 & -1.39 & 0.1646 & 0.8415 \\
\hline & Country 16 & -0.1062 & 0.1032 & -0.3084 & 0.0960 & -1.03 & 0.3031 & 0.8992 \\
\hline & Country 17 & -0.2143 & 0.1321 & -0.4733 & 0.0447 & -1.62 & 0.1048 & 0.8071 \\
\hline & Country 18 & -0.2610 & 0.0697 & -0.3976 & -0.1244 & -3.74 & 0.0002 & 0.7703 \\
\hline & Country 19 & -0.2388 & 0.1078 & -0.4500 & -0.0275 & -2.22 & 0.0267 & 0.7876 \\
\hline $\log (1+$ consumption $)$ day -1 & & 0.0505 & 0.0079 & 0.0350 & 0.0660 & 6.38 & $<0.0001$ & 1.0518 \\
\hline $\log (1+$ consumption $)$ day -2 & & -0.0022 & 0.0072 & -0.0163 & 0.0119 & -0.31 & 0.7590 & 0.9978 \\
\hline $\log (1+$ consumption $)$ day -7 & & 0.0386 & 0.0097 & 0.0196 & 0.0576 & 3.98 & $<0.0001$ & 1.0394 \\
\hline
\end{tabular}

Illustrative example: assuming a female patient, aged 60, from country 1, not previously treated, who did not drink the day before, who drank $80 \mathrm{~g} 2$ days before and $30 \mathrm{~g} 7$ days before, the predicted number of grams on a drinking Thursday would be calculated as:

$\mu=e^{4.9365-60 \times 0.0047-0.2298-0.1847-\ln (1+80) \times 0.0022+\ln (1+30) \times 0.0386}=78.5 \mathrm{~g}$.

the total number of parameters used in the model. An illustrative example demonstrating the use of the linear combination in the analysis is provided in the footnote of table 2.

The resulting mean alcohol consumption was incorporated into the calculation for $p$ in the negative binomial distribution (equation 4).

$$
p=\left(\frac{1 / k}{1 / k+\mu}\right)^{1 / k},
$$

where $p$ is the probability of not consuming alcohol, $k$ is the dispersion and $\mu$ is the mean amount of alcohol consumed as calculated in equation 3. The dispersion variable $k$ of a random variable $Y$ following a negative binomial distribution is defined according to the formula: $\operatorname{Variance}(Y)=\mu+k \mu^{2}$.

Predicted Clinical Relevance of Alcohol Reduction
Alcohol consumption data from the 28-day baseline periods of three Lundbeck-sponsored nalmefene phase III clinical trials (ESENSE1, ESENSE2 and SENSE) were available to obtain the statistical equations used in the model to simulate individual alcohol consumption of untreated alcohol-dependent patients. Figure 2 presents the average alcohol consumption of patients during the 28 days before their baseline visit in the three nalmefene clinical trials. The clinical trials were randomised, double-blind and placebo-controlled studies with alcohol-dependent patients from 19 European countries [24-28]. These trials were used in this modelling context because the patient populations were those for whom reduction of alcohol consumption is a relevant treatment goal; specifically, alcohol-dependent patients with high DRLs without physical withdrawal symptoms and who do not require immediate detoxification, in line with nalmefene's indication $[23,39]$. Since patient baseline characteristics between the three studies were sim- 
Fig. 2. Average alcohol consumption of patients during the 28 days before baseline visit in the three nalmefene clinical trials.

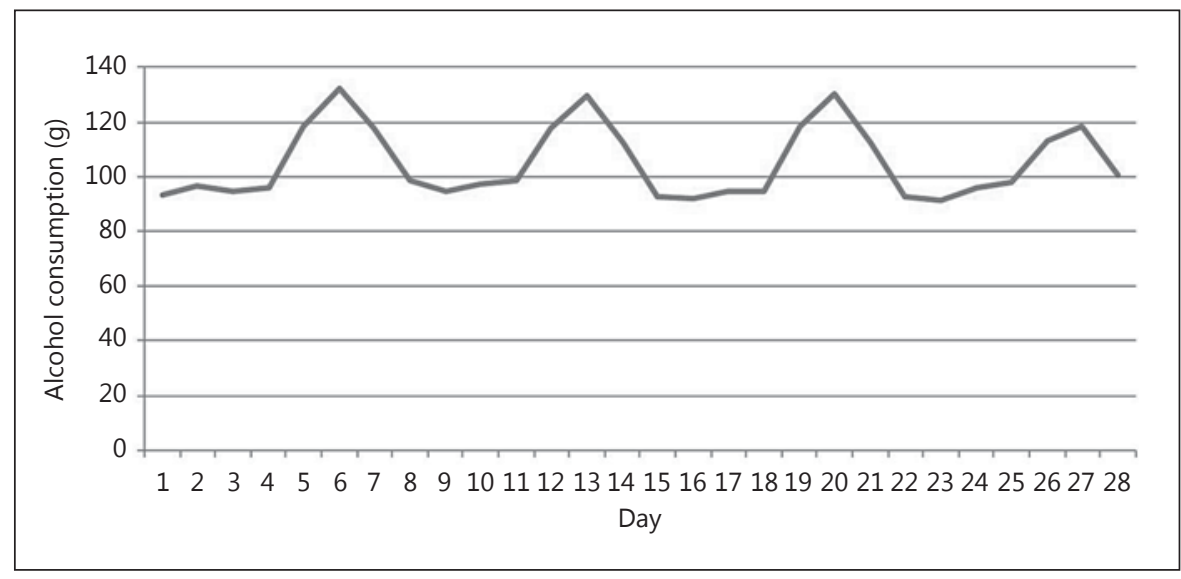

Table 3. Pooled baseline patient characteristics from nalmefene clinical trials (licensed population)

\begin{tabular}{lc}
\hline Variable & Value $(\mathrm{n}=824)^{1}$ \\
\hline Male & $565(69)$ \\
Age, years & $48.0 \pm 10.8$ \\
Drinking level at baseline & $350(42)$ \\
$\quad$ High & $474(58)$ \\
$\quad$ Very high & $21.8 \pm 6.2$ \\
HDDs per month at baseline, $\mathrm{n}$ & $104.1 \pm 45.0$ \\
TAC at baseline, $g$ & \\
\hline
\end{tabular}

Data are presented as number with percentage in parentheses, or mean value $\pm \mathrm{SD}$.

${ }^{1}$ Pooled data from ESENSE1, ESENSE2 and SENSE trials.

ilar for the patient population under nalmefene's license, data from these studies were pooled for use in this model. Table 3 illustrates the pooled baseline patient characteristics from the nalmefene clinical trials for the licensed population. Baseline characteristics and alcohol consumption from the 28-day baseline trial periods were sampled, with replacement, from trial datasets of 824 patients drinking at high or very high DRLs at both baseline (screening) and randomisation to create a model cohort of 200,000 patients. This patient population was the full analysis set. A simulation of 200,000 patients was considered to provide stable results with a standard error of mean TAC below $0.5 \%$ of the mean.

The model required a run-in period of at least 7 days, as the level of alcohol consumption on previous days was a key component in the statistical equations. The run-in period consisted of individual mean consumption on each day of the second and third weeks of baseline clinical trial data. Although alcohol consumption data were available from the full 28-day baseline period, ultimately model parameters were estimated based on baseline data from days 8-21, as for days 1-7 previous alcohol consumption data necessary for predictive purposes were not available for all patients. Furthermore, data from days 22-28 were found not to be predictive of future alcohol consumption without treatment, as many patients had reduced their intake immediately prior to trial enrolment in anticipation of treatment (fig. 2).

Simulation of alcohol consumption was based on random numbers, with the model generating two random numbers from a uniform distribution of $0-1$ for each patient and for each day. The first random number was used to simulate intake of alcohol (yes or no); if the random number was lower than the probability of drinking obtained from the logistic model, the patient was assumed to consume alcohol. The second random number was used to simulate the amount of alcohol consumed in grams, conditional upon a decision being made to drink. The simulated amount was the quantile of the distribution of alcohol consumption predicted by the negative binomial model corresponding to the random number.

\section{Simulating Events}

The model outcomes were inpatient consultation episodes for alcohol-attributable events. Included events were those with a well-documented association of risk with level of alcohol consumption and, based on the alcohol-dependent population included in the nalmefene trials, those with a high incidence of hospitalisation in alcohol-dependent patients over a 1-year time horizon. Both 'short-term' events, resulting from a single episode of heavy alcohol consumption, and 'long-term' events, resulting from continuous alcohol consumption over time, were considered in the model. Short-term events, such as transport injuries, other injuries, ischaemic heart disease and ischaemic stroke, are clinically most sensitive to HDDs and were modelled based on simulated alcohol consumption over each day. In contrast, long-term events, such as haemorrhagic stroke, liver cirrhosis, pancreatitis and lower respiratory infections, are clinically most sensitive to TAC and long-term consumption of alcohol, and were therefore modelled based on average alcohol consumption over a clinically relevant time period (table 4 ).

Two equations were used to calculate the incidence of alcoholattributable diseases and injuries. The first (equation 5) simply calculated the general population risks of each disease or injury included in the model, using English data. Probabilities of inpatient consultation episodes over the course of 1 year for the general population were taken from the hospital episodes statistics (HES) for 2010-2011 [56]. Relevant ICD-10 codes were used to identify inpatient consultation episodes for each type of disease or injury (ta- 
Table 4. Calculation of inpatient consultation episodes for alcohol-attributable events in the model

\begin{tabular}{|c|c|c|c|c|}
\hline $\begin{array}{l}\text { Alcohol- } \\
\text { attributable } \\
\text { event }\end{array}$ & ICD-10 Code & $\begin{array}{l}\text { Source(s) for determining the } \\
\text { risk relations of each disease or } \\
\text { injury to level or pattern of } \\
\text { alcohol consumption }\end{array}$ & $\begin{array}{l}\text { Relevant time period in line } \\
\text { with the physiopathology of } \\
\text { the development and } \\
\text { occurrence of the event }\end{array}$ & $\begin{array}{l}\text { Calculation of yearly inpatient consultation } \\
\text { episodes }\end{array}$ \\
\hline $\begin{array}{l}\text { Transport- } \\
\text { related } \\
\text { injuries }\end{array}$ & $(\text { see footnote })^{1}$ & $\begin{array}{l}\text { For relative risk: Taylor et al. } \\
\text { [57] } \\
\text { For methodology: Taylor et al. } \\
{[51]}\end{array}$ & Daily & $\begin{array}{l}\text { Calculated for each patient for each day } \\
\text { according to alcohol consumption in grams } \\
\text { during that day. } \\
\text { In line with earlier publications on harmful } \\
\text { events from drinking, it was not realistic to } \\
\text { assume that patients would experience increased } \\
\text { risk of transport injuries and injuries other than } \\
\text { transport for the entire day, because patients } \\
\text { must be in a specific environment to experience } \\
\text { the event [11, 50]. Thus, an adjustment of hours } \\
\text { drinking per day was incorporated into the } \\
\text { model's calculations for these events. In the } \\
\text { analysis, the hours of drinking per day and thus } \\
\text { the time the patient is subject to a risk of } \\
\text { experiencing the event is therefore set to } 3 \text { h. } \\
\text { The number of inpatient consultation episodes } \\
\text { over } 12 \text { months was obtained by summing daily } \\
\text { probabilities of inpatient consultation episodes. }\end{array}$ \\
\hline
\end{tabular}

\begin{tabular}{lllll}
\hline $\begin{array}{l}\text { Non- } \\
\text { transport- }\end{array}$ & Rest of V-series ${ }^{2}$, & For relative risk: Taylor et al. & Daily & C57] \\
related & X00-X39, & & $\begin{array}{l}\text { Calculated in the same manner as for transport- } \\
\text { related injuries. }\end{array}$
\end{tabular}

X00-X39, X40-X84, For methodology: Taylor et al.

injuries $\quad \mathrm{X} 85-\mathrm{Y} 09, \mathrm{Y} 40-\mathrm{Y} 86,[51]$

Y87.0, Y87.1, Y88

and $\mathrm{Y} 89$

\begin{tabular}{llll}
\hline $\begin{array}{l}\text { Ischaemic } \\
\text { stroke }\end{array}$ & I60-I62 & Patra et al. [45] & Daily \\
& & For pattern of alcohol \\
& consumption: Guiraud et al. & \\
& &
\end{tabular}

during that day. The model therefore accoun for occurrences triggered by significant daily alcohol consumption. The number of inpatient consultation episodes over 12 months was obtained by summing daily probabilities of inpatient consultation episodes.

\begin{tabular}{|c|c|c|c|c|}
\hline $\begin{array}{l}\text { Ischaemic } \\
\text { myocardial } \\
\text { infarction }\end{array}$ & I20-I25 & $\begin{array}{l}\text { For pattern of alcohol } \\
\text { consumption: Roerecke and } \\
\text { Rehm [43] } \\
\text { For volume of alcohol } \\
\text { consumption: Roerecke and } \\
\text { Rehm [58] }\end{array}$ & Daily & $\begin{array}{l}\text { Calculated in the same manner as for ischaemic } \\
\text { stroke, as both events have similar } \\
\text { physiopathologies of occurrence, and have } \\
\text { shown similar risks epidemiologically for being } \\
\text { triggered by heavy drinking. }\end{array}$ \\
\hline $\begin{array}{l}\text { Liver } \\
\text { cirrhosis }\end{array}$ & K70, K74 & Rehm et al. [47] & Two 6-month periods & $\begin{array}{l}\text { Calculated for each patient over two 6-month } \\
\text { periods, to account for the progressive } \\
\text { development of the condition with alcohol } \\
\text { consumption. Average daily consumption was } \\
\text { estimated over the two periods and the relative } \\
\text { risk determined at the end of each period. The } \\
\text { number of inpatient consultation episodes over } \\
12 \text { months was obtained by summing the } \\
\text { probabilities over the two } 6 \text {-month periods. }\end{array}$ \\
\hline Pancreatitis & K85, K86.1 & Irving et al. [48] & Two 6-month periods & $\begin{array}{l}\text { Calculated in the same manner as for liver } \\
\text { cirrhosis. The model did not distinguish between } \\
\text { acute and chronic pancreatitis, with inpatient } \\
\text { consultation episodes for acute and chronic } \\
\text { pancreatitis combined and the same relative risk } \\
\text { function applied to both types of event. }\end{array}$ \\
\hline
\end{tabular}


Table 4 (continued)

\begin{tabular}{|c|c|c|c|}
\hline $\begin{array}{l}\text { Haemorrhagic I63-I66 } \\
\text { stroke }\end{array}$ & Patra et al. [45] & Two 6-month periods & $\begin{array}{l}\text { Calculated in the same manner as for liver } \\
\text { cirrhosis. }\end{array}$ \\
\hline $\begin{array}{l}\text { Lower } \\
\text { respiratory } \\
\text { infection }\end{array}$ & Samokhvalov et al. [49] & Twelve 1-month periods & $\begin{array}{l}\text { Average daily consumption was estimated for } \\
\text { each patient over twelve } 1 \text {-month periods and } \\
\text { the relative risk determined at the end of each } \\
\text { period. The number of inpatient consultation } \\
\text { episodes over } 1 \text { year was obtained by summing } \\
\text { the probabilities over the twelve periods. }\end{array}$ \\
\hline
\end{tabular}

${ }^{1}$ V021-V029, V031-V039, V041-V049, V092, V093, V123-V129, V133-V139, V143-V149, V194-V196, V203-V209, V213-V219, V223-V229, V233V239, V243-V249,V253-V259, V263-V269, V273-V279, V283-V289, V294-V299, V304-V309, V314-V319, V324-V329, V334-V339, V344-V349, V354-V359, V364-V369, V374-V379, V384-V389, V394-V399, V404-V409, V414-V419, V424-V429, V434-V439, V444-V449, V454-V459, V464V469, V474-V479, V484-V489, V494-V499, V504-V509, V514-V519, V524-V529, V534-V539, V544-V549, V554-V559, V564-V569, V574-V579, V584-V589, V594-V599, V604-V609, V614-V619, V624-V629, V634-V639, V644-V649, V654-V659, V664-V669, V674-V679, V684-V689, V694V699, V704-V709, V714-V719, V724-V729, V734-V739, V744-V749, V754-V759, V764-V769, V774-V779, V784-V789, V794-V799, V803-V805, V811, V821, V830-V833, V840-V843, V850-V853, V860-V863, V870-V878, V892.

${ }^{2} \mathrm{~V}$ series minus footnote 1 .

ble 4). Specifically, the HES variable 'finished consultant episodes' (FCE) was used, which represents an episode of care under the supervision of one consultant, and can be used as a proxy for the number of diagnoses of alcohol-attributable diseases or injuries during hospital stays. For injuries, the denominator was the total male and female population size in England in 2010, while for diseases the denominator was the number of males and females aged 18 years or over in England in 2010, since few relevant diseaserelated episodes were recorded in children. The risks for males and females were calculated separately.

$$
\text { General Population's Disease Risk }(i)=\frac{\text { Number of events over } 1 \text { year }}{\text { Country's total population }} \text {. }
$$

Published meta-analyses assessing the impact of alcohol consumption were used to develop risk equations to calculate the relative risks of disease and injury for patients with a given daily alcohol consumption compared to the general population [43, 45, 47-49, $51,57,58]$. These risk equations were developed by the Canadian Centre for Addiction and Mental Health (CAMH) using published meta-analyses based on systematic literature reviews that included international literature (table 4), and were previously used for a population-based analysis [16]. Calculated relative risk ratios at a given level of alcohol consumption were then multiplied by the risk of the event in the general population derived in equation 5 (equation 6). The risk ratio was applied considering alcohol consumption over a time period in accordance with the physiopathology of the development and occurrence of the event; for example, grams of alcohol consumed per day, average daily consumption over the previous month, or average daily consumption over the previous 6 months (table 4). Probabilities of clinical events for each patient were summed over 12 months and then aggregated over groups of patients defined by the number of HDDs and TAC across 12 months. This was performed for men and women separately, and then combined based on the proportions of males and females in the nalmefene clinical trials. An illustrative example of how the risk equations were implemented in the model is given for liver cirrhosis in online supplementary table 1 (for all online suppl. material, see www.karger.com/doi/10.1159/000362408).
Personal Disease Risk $(i)_{T 1}$ Patient $_{(z)}$

$=$ General Population's Disease Risk $(i)$

$\times$ RRDisease $(i)\left(x_{T 1}\right)$ Patient $_{z}$,

where Personal Disease $\operatorname{Risk}(i)_{T 1}$ Patient $_{(z)}$ is the risk of disease $(i)$ for a time $T 1$ for Patient $z$, and RRDisease $(i)\left(x_{T 1}\right)$ Patient $_{z}$ is the relative risk of disease $(i)$ given an alcohol consumption at time $T 1$ of $x$ grams for a Patient $z$ with $\mathrm{AD}$, versus the general population.

\section{Sensitivity Analysis}

Deterministic sensitivity analyses were conducted by varying statistically uncertain parameters of the relative risk equations used to derive the incidence of alcohol-attributable events according to the level of alcohol consumption. The analyses were run using the lower bound of variance of all relative risk function parameters with statistical uncertainty simultaneously, and then the upper bound of the variance of all such parameters simultaneously. When different functions were used for males and females, parameters were changed for males and females simultaneously.

Uncertainty around the parameters of the logistic and negative binomial regression models was assessed by a probabilistic sensitivity analysis. Each parameter was associated to a normal distribution with a mean equal to the value of the estimate ('Estimate' column in tables 1 and 2) and using the standard error around the estimate ('Standard error' column in tables 1 and 2). The alcohol consumption of 200,000 patients was then simulated, as well as their alcohol-related events. Confidence intervals around the number of events were produced using 2.5 and 97.5 percentiles of the results of the simulations.

\section{External Validation of Results}

An external validation of the model results was performed, with the incidence of hospitalisation events in the alcohol-dependent population calculated using equation 7 . For the external validation, the relative risks of alcohol-attributable events were derived from a single source in the published literature for each event, as opposed to being based on a risk formula developed from meta-analysis. Data on the incidence of disease events in the UK general population in terms of inpatient admission rates were tak- 
en from the European Hospital Morbidity Database (HMDB)WHO Regional Office for Europe [59]. Diseases were identified with the same ICD-10 codes as used in the model. The incidences of events estimated in this way were compared with the incidences of events obtained in the model.

Incidence of hospitalisation events in the alcoholic population $=$ Relative risk associated with alcohol consumption $\times$

Incidence of hospitalisation events in the general population.

\section{Results}

\section{Simulating Alcohol Consumption - Probability of}

Consuming Alcohol

The clinical trials used in the run-in period of the model provided data for 11,536 patient days, including 9,888 drinking days. The logistic model for probability of drinking was estimated based on these data (table 1). In the model, the probability of drinking significantly increased with age (odds ratio $=1.0122$, meaning that the odds of drinking increased by approximately $1.22 \%$ with each additional year of age when all other parameters were equal). However, there was no significant difference between the sexes. In the model, the probability of drinking was higher on Fridays, with the odds of drinking being $10.6 \%$ higher on Fridays compared to Saturdays, and 20.4$45.5 \%$ lower on other days. Odds of drinking were reduced by $25.8 \%$ in previously treated patients compared to treatment-naïve patients. There was significant variability between countries in the probability of drinking. All other parameters were non-significant, but were maintained in the model for adjustment purposes.

\section{Simulating Alcohol Consumption - Amount of Alcohol Consumed}

The negative binomial model for the amount of alcohol consumed on drinking days was estimated based on data describing 9,888 drinking days from the run-in period (table 2). The model was run without random patient effects initially, in order to estimate the dispersion. The dispersion parameter was estimated at 1.2667. In the model, the coefficient of age was negative, implying that the mean quantity of alcohol consumed on drinking days decreased with age. The associated ratio of 0.9953 meant that consumption was reduced by $0.47 \%$ with each year of age. The model also showed that female patients drank $20.5 \%$ less compared to males on an average drinking day, all other parameters being equal.

In the model, the quantity of alcohol consumed was highest on Saturdays, conditional upon drinking, with

Predicted Clinical Relevance of Alcoho Reduction consumed quantities 3.8\% (Friday) to $17.5 \%$ (Monday) lower on other days. The quantity of alcohol consumed varied between countries, being 23.0\% lower in the country with the lowest daily consumption compared to the reference country. The quantity of alcohol consumed increased with consumption on the previous day and on the same day of the previous week. For example, the mean quantity of alcohol was $27.6 \%$ higher in a patient who drank $123 \mathrm{~g}$ on the previous day (average consumption on a drinking day) compared to a patient who did not drink, all other parameters being equal. Finally, previously-treated patients drank $12.9 \%$ more than treatment-naïve patients, all other parameters being equal.

\section{Clinical Relevance of a Reduction in the Number of HDDs per Year}

For all diseases and injuries, the number of events increased with the number of HDDs per year for the whole simulated cohort of untreated alcohol-dependent patients (table 5). In mixed model repeated measures (MMRM) analyses of the nalmefene clinical trials, the number of HDDs per month in patients receiving nalmefene fell from 23 at baseline to 11 at month 6 in ESENSE1 [28], from 23 at baseline to 10 at month 6 in ESENSE2 [28], and from 19 at baseline to 7 at month 13 in SENSE [25]. The predictive microsimulation model suggested that a reduction from 23 HDDs per month to 10 or 11 HDDs per month (the equivalent of a reduction from $>220$ HDDs per year to 120-140 HDDs per year), as seen in ESENSE1 and ESENSE2, would result in the annual avoidance of 6,813 (95\% CI 6,466-6,847) alcoholattributable diseases and injuries in a cohort of 100,000 alcohol-dependent patients. This figure comprised 481 (95\% CI 478-484) events of ischaemic heart disease, 152 (95\% CI 150-152) events of ischaemic stroke, 357 (95\% CI 352-358) events of traffic-related injuries, 2,140 (95\% CI 2,126-2,148) events of non-traffic-related injuries, 873 (95\% CI 836-883) events of liver cirrhosis, 2,016 (95\% CI 1,734-2,030) events of pancreatitis, 659 (95\% CI 643$671)$ events of lower respiratory infection and 135 (95\% CI 132-137) events of haemorrhagic stroke. The numbers of avoided events were similar when estimating the clinical relevance of reductions in HDDs as observed with nalmefene in the SENSE trial: a reduction of 19 HDDs per month (>220 HDDs per year) to 7 HDDs per month $(<100$ HDDs per year) was predicted to result in the annual avoidance of 9,004 (95\% CI 8,656-9,038) alcoholattributable diseases and injuries per 100,000 alcohol-dependent patients. 
Table 5. Number of events per 100,000 patient years by number of HDDs (males and females)

\begin{tabular}{lllllllll}
\hline $\begin{array}{l}\text { HDDs per } \\
\text { year, days }\end{array}$ & $\begin{array}{l}\text { Ischaemic } \\
\text { heart disease }\end{array}$ & $\begin{array}{l}\text { Ischaemic } \\
\text { stroke }\end{array}$ & $\begin{array}{l}\text { Traffic } \\
\text { injuries }\end{array}$ & $\begin{array}{l}\text { Other } \\
\text { injuries }\end{array}$ & Cirrhosis & Pancreatitis & $\begin{array}{l}\text { Lower respiratory } \\
\text { infection }\end{array}$ & $\begin{array}{l}\text { Haemorrhagic } \\
\text { stroke }\end{array}$ \\
\hline$<100$ & 1,563 & 494 & 303 & 2,434 & 330 & 141 & 1,827 & 149 \\
$100-120$ & 1,707 & 538 & 398 & 3,085 & 428 & 188 & 1,957 & 171 \\
$120-140$ & 1,819 & 572 & 465 & 3,602 & 505 & 235 & 2,046 & 2,120 \\
$140-160$ & 1,928 & 606 & 531 & 4,112 & 582 & 291 & 2,217 & 223 \\
$160-180$ & 2,027 & 637 & 598 & 4,553 & 686 & 391 & 2,340 & 2,523 \\
$180-200$ & 2,118 & 666 & 668 & 4,953 & 836 & 596 & 1,136 & 2,705 \\
$200-220$ & 2,211 & 695 & 747 & 5,361 & 1,084 & 1,136 & 323 \\
$>220$ & 2,300 & 724 & 822 & 5,742 & 1,378 & 2,251 & \\
\hline
\end{tabular}

This table was presented in the nalmefene European public assessment report [39].

Table 6. Number of events per 100,000 patient years by TAC category per year (males and females)

\begin{tabular}{|c|c|c|c|c|c|c|c|c|}
\hline$<15,000$ & 1,465 & 467 & 239 & 2,034 & 269 & 116 & 1,731 & 134 \\
\hline $15,000-18,000$ & 1,562 & 498 & 304 & 2,492 & 322 & 132 & 1,812 & 149 \\
\hline $18,000-21,000$ & 1,640 & 524 & 358 & 2,881 & 370 & 150 & 1,879 & 161 \\
\hline $21,000-24,000$ & 1,721 & 551 & 412 & 3,278 & 424 & 175 & 1,950 & 174 \\
\hline $30,000-33,000$ & 1,964 & 626 & 568 & 4,383 & 621 & 303 & 2,173 & 221 \\
\hline $33,000-36,000$ & 2,024 & 645 & 613 & 4,652 & 703 & 380 & 2,254 & 239 \\
\hline $36,000-39,000$ & 2,076 & 661 & 655 & 4,887 & 794 & 485 & 2,340 & 259 \\
\hline $39,000-42,000$ & 2,122 & 675 & 693 & 5,089 & 899 & 636 & 2,435 & 280 \\
\hline $42,000-45,000$ & 2,157 & 686 & 726 & 5,248 & 1,017 & 866 & 2,528 & 303 \\
\hline$\geq 45,000$ & 2,216 & 704 & 773 & 5,508 & 1,234 & 1,435 & 2,691 & 336 \\
\hline
\end{tabular}

This table was presented in the nalmefene European public assessment report [39].

At the end of the nalmefene clinical studies, in MMRM analyses the difference in the number of HDDs per month between nalmefene and placebo was 3.7 in ESENSE1 [28], 2.7 in ESENSE2 [28] and 3.6 in SENSE [25]. Assuming a conservative reduction in alcohol consumption achieved with nalmefene versus placebo of 2-3 HDDs per month (conservatively corresponding to $20 \mathrm{HDDs}$ per year), the model was used to estimate the difference between the number of events in a cohort of 100,000 alcohol-dependent patients with 120-140 HDDs per year (equivalent to the mean number of HDDs per year in the ESENSE1 nalmefene arm at month 6) and a cohort of 100,000 alcohol-dependent patients in the adjacent, higher category of 140-160 HDDs per year. The difference was 941 (95\%
CI 933-945) alcohol-attributable diseases and injuries per 100,000 alcohol-dependent patients, comprising 109 (95\% CI 109-110) events of ischaemic heart disease, 34 (95\% CI 34-34) events of ischaemic stroke, 66 (95\% CI 65-66) events of traffic-related injuries, 510 (95\% CI 507513 ) events of non-traffic-related injuries, 77 (95\% CI 7577) events of liver cirrhosis, 56 (95\% CI 54-56) events of pancreatitis, 74 (95\% CI 71-74) events of lower respiratory infection and 15 (95\% CI 15-16) events of haemorrhagic stroke.

\section{Clinical Relevance of a Reduction in TAC per Year}

For all diseases and injuries, the number of events increased as TAC per year increased for the whole simu- 
lated cohort of untreated alcohol-dependent patients (table 6). Again, these results were assessed in terms of MMRM results from the three nalmefene phase III clinical trials for the licensed population. In ESENSE1, mean TAC in patients receiving nalmefene was $102 \mathrm{~g} /$ day at baseline compared to $44 \mathrm{~g} /$ day at the end of the study [28], corresponding to the annual TAC categories of 36,000$39,000 \mathrm{~g}$ and $15,000-18,000 \mathrm{~g}$, respectively. The model estimated that the difference between these two cohorts over the course of 1 year was 4,886 (95\% CI 4,882-4,904) events per 100,000 alcohol-dependent patients. As with HDDs, a large number of these events were non-trafficrelated injuries $(2,396 ; 95 \%$ CI 2,392-2,406), with the rest comprising ischaemic heart disease (514 events; 95\% CI 514-517), ischaemic stroke (163 events; 95\% CI 163164), traffic-related injuries (351 events; 95\% CI 349351 ), liver cirrhosis ( 472 events; 95\% CI 472-473), pancreatitis (353 events; 95\% CI 352-354), lower respiratory infection (528 events; 95\% CI 528-531) and haemorrhagic stroke (110 events; 95\% CI 110-110).

The numbers of avoided events were similar when considering data from ESENSE2 and SENSE. In ESENSE2, mean TAC in nalmefene-treated patients decreased from $113 \mathrm{~g} /$ day at baseline to $43 \mathrm{~g} /$ day at the end of the study, corresponding to the annual TAC categories of $39,000-42,000 \mathrm{~g}$ and $15,000-18,000 \mathrm{~g}$, respectively [28]. The model estimated that the difference between these two cohorts over the course of 1 year was 5,558 (95\% CI 5,533-5,566) events per 100,000 alcohol-dependent patients. In SENSE, mean TAC in nalmefene-treated patients was $100 \mathrm{~g} /$ day at baseline and $33 \mathrm{~g} /$ day at the end of the study [25]. The difference between the annual TAC categories of 36,000-39,000 $\mathrm{g}$ and $<15,000 \mathrm{~g}$ that these daily consumptions correspond to were estimated to result in the annual avoidance of 5,702 (95\% CI 5,695$5,725)$ alcohol-attributable events per 100,000 alcoholdependent patients in the model.

At the end of the nalmefene clinical studies, the differences in TAC by MMRM analysis between nalmefene and placebo were $18.3 \mathrm{~g} /$ day, $10.3 \mathrm{~g} /$ day and $17.3 \mathrm{~g} /$ day in ESENSE1, ESENSE2 and SENSE, respectively [25, 28]. Assuming a conservative reduction in alcohol consumption achieved with nalmefene versus placebo of $10 \mathrm{~g} /$ day (conservatively corresponding to 3,000 g/year), the predictive microsimulation model estimated that between patients in the 15,000-18,000 g/year category (equivalent to mean TAC per year in the ESENSE1 nalmefene arm at the end of the trial) and the 18,000-21,000 g/year category, there would be an annual difference of 692 (95\% CI 678-698) alcohol-attributable diseases and injuries per

Predicted Clinical Relevance of Alcoho Reduction
100,000 alcohol-dependent patients. This figure consisted of 78 (95\% CI 76-79) events of ischaemic heart disease, 26 (95\% CI 25-26) events of ischaemic stroke, 54 (95\% CI 52-54) events of traffic-related injuries, 389 (95\% CI 378392) events of non-traffic-related injuries, 48 (95\% CI $48-$ 49) events of liver cirrhosis, 18 (95\% CI 18-19) events of pancreatitis, 67 (95\% CI 67-70) events of lower respiratory infection and 12 (95\% CI 12-12) events of haemorrhagic stroke.

\section{Sensitivity Analyses}

In all deterministic sensitivity analyses, varying statistically uncertain parameters of the relative risk equations used to derive the incidence of alcohol-attributable events according to the level of alcohol consumption resulted in the numbers of events per 100,000 patient years increasing accordingly with the number of HDDs and TAC per year, consistent with the base case results (online suppl. tables 2 and 3). For all diseases and injuries, the difference in numbers of events per 100,000 patient years using the minimum and maximum parameter values increased in categories with higher HDDs and TAC. For both HDDs and TAC, the events with the largest ranges between minimum case and maximum case were non-transport-related injuries, pneumonia and pancreatitis. Even in the minimum case scenarios for all diseases and injuries, the number of events avoided by reducing HDD and TAC remained considerable. For example, using the minimum case scenarios for females for all alcohol-attributable events, a reduction in annual TAC from the 36,000$39,000 \mathrm{~g} /$ year category to the $15,000-18,000 \mathrm{~g} /$ year category, as seen from baseline to the end of the trial in the nalmefene arm in ESENSE1, still predicted 2,280 events per 100,000 patient years being avoided overall, with the lowest number of events avoided being predicted for ischaemic strokes (55 events). For males, this same reduction in annual TAC was estimated to result in 2,547 events per 100,000 patient years avoided overall, with the lowest number of events avoided being predicted for haemorrhagic stroke (42 events).

In the probabilistic sensitivity analysis assessing the parameters used in the alcohol consumption equations, 2.5 and 97.5 percentiles of the results in terms of number of events per 100,000 patient years are presented in online supplementary tables 4 and 5 . These intervals demonstrate a relatively small distribution of the results, explained by the statistical power resulting from $11,536 \mathrm{pa}-$ tient days and 9,888 drinking days provided by using data sourced from the nalmefene clinical trials for simulating alcohol consumption. For both HDDs and TAC, the 
Table 7. Number of predicted hospitalisation events using data from a targeted review of the literature and WHO-HMDB compared to the model

\begin{tabular}{|c|c|c|c|c|c|c|}
\hline Disease or injury & \multicolumn{5}{|c|}{ External validation (targeted literature search + WHO-HMDB) } & $\begin{array}{l}\text { Model } \\
\text { events in alcoholic } \\
\text { population }^{4}, \mathrm{n}\end{array}$ \\
\hline $\begin{array}{l}\text { Ischaemic heart } \\
\text { disease }\end{array}$ & $\begin{array}{l}\text { Roerecke and Rehm } \\
{[43], 2010}\end{array}$ & $>60$ & 1.45 & 518 & 751 & $\sim 1,100-1,200$ \\
\hline Ischaemic stroke & $\begin{array}{l}\text { Reynolds et al. [69], } \\
2003\end{array}$ & $>60$ & 1.69 & 201 & 340 & $\sim 250$ \\
\hline $\begin{array}{l}\text { Injury } \\
\text { (traffic + others) }\end{array}$ & $\begin{array}{l}\text { Corrao et al. [70], } \\
1999\end{array}$ & 100 & 4.00 & 1,207 & 4,827 & $\sim 4,300$ \\
\hline $\begin{array}{l}\text { Liver cirrhosis } \\
\text { (men) }\end{array}$ & $\begin{array}{l}\text { Rehm et al. [47], } \\
2009\end{array}$ & $>60$ & 5.00 & 59 & 295 & $\sim 200$ \\
\hline $\begin{array}{l}\text { Liver cirrhosis } \\
\text { (women) }\end{array}$ & $\begin{array}{l}\text { Rehm et al. [47], } \\
2009\end{array}$ & $>60$ & 6.10 & 31 & 189 & $\sim 200-250$ \\
\hline $\begin{array}{l}\text { Lower respiratory } \\
\text { infection }\end{array}$ & $\begin{array}{l}\text { Rehm et al. [14], } \\
2010\end{array}$ & 100 & 1.61 & 618 & 995 & $\sim 1,400$ \\
\hline $\begin{array}{l}\text { Haemorrhagic } \\
\text { stroke }\end{array}$ & $\begin{array}{l}\text { Reynolds et al. [69], } \\
2003\end{array}$ & $>60$ & 2.18 & 58 & 126 & $\sim 100$ \\
\hline \multicolumn{7}{|c|}{ 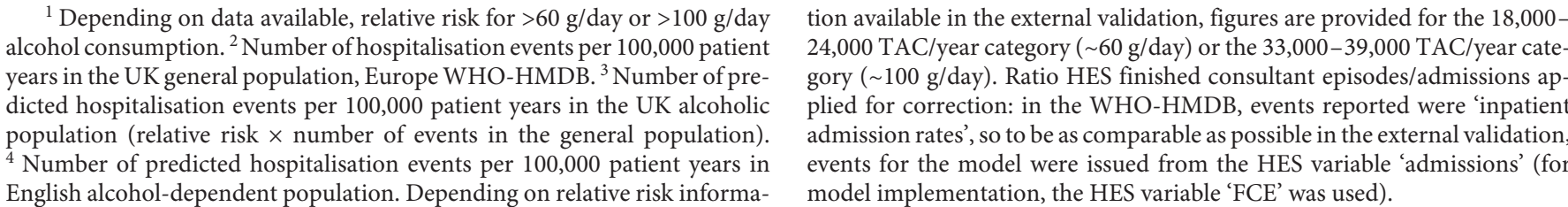 } \\
\hline
\end{tabular}

events with the largest ranges between minimum and maximum case were non-transport-related injuries, liver cirrhosis and pancreatitis.

\section{External Validation}

A comparison of hospitalisation events predicted by the external validation and by the model is provided in table 7. Compared to the external validation results, the model predicted slightly higher numbers of events for lower respiratory infection and ischaemic heart disease (ratio of model results to external validation results $\sim 1.5$ ) and lower numbers of events for ischaemic stroke and cirrhosis in men (ratio 0.7). However, the model and the external validation predicted similar numbers of events for haemorrhagic stroke, injury, pancreatitis and cirrhosis in women (ratio 0.8, 0.9, 1.0 and 1.2, respectively).

\section{Discussion}

Results from this microsimulation model have indicated that the risks of experiencing ischaemic heart disease, ischaemic and haemorrhagic stroke, cirrhosis, pancreatitis, lower respiratory infection, traffic-related injuries and non-traffic-related injuries vary considerably with the frequency of HDDs and TAC per month in patients with $\mathrm{AD}$. To contextualise these results, the model predicted that a 20-day per year reduction in the number of HDDs, as achieved with nalmefene compared with placebo in clinical trials, would be associated with a clinically relevant reduction in the number of harmful alcohol-attributable events per 100,000 patient years. Similarly, a 3,000 g/year reduction in TAC, again as achieved with nalmefene versus placebo in clinical trials, was predicted to result in a clinically relevant reduction in the incidence of harmful events. All model outcomes were 
robust to sensitivity analysis and were validated using external data sources.

While these findings are in line with previous population-level studies investigating the impact of alcohol reduction on mortality [29-33], to our knowledge this is the first study to quantitatively model the association between morbidity and the level of alcohol consumption for alcohol-dependent patients at the individual level. It corroborates recent results from meta-analyses of cohort studies that reduction of drinking in people with alcohol problems $[34,60]$ and reduction of drinking in people being treated for $\mathrm{AD}$ may result in significant mortality gains [61]. However, the latter study was unable to measure the association between the level of reduction of drinking and mortality as the underlying literature did not contain this information.

Given the recent acknowledgement of alcohol reduction as a valid treatment goal for alcohol-dependent patients by the EMA [19], this study is timely in demonstrating the clinical relevance of treatments successfully affecting reductions in alcohol consumption, such as nalmefene. During the EMA marketing authorisation process for nalmefene, this predictive microsimulation model and the model results were presented to the CHMP. The Scientific Advisory Group noted that the model showed that 'even a moderate decrease in drinking levels might be associated with a decrease in both harmful events (e.g. mortality rates, accidents) and a decrease in the relative risk of the medical issues typically linked to excessive alcohol drinking (e.g. liver cirrhosis)' [39].

This study employed a predictive microsimulation modelling approach, which is novel in this therapeutic area. Such an approach is well suited when modelling alcohol-dependent patients as the relationships between alcohol consumption per time period and risks of disease are non-linear, necessitating the accurate simulation of the drinking patterns of individual patients. Microsimulation also allowed for heterogeneity in consumption between individual patients. It was recently reported that such an approach is being employed by the Organisation for Economic Cooperation and Development (OECD) to evaluate the cost-effectiveness of interventions for $\mathrm{AD}$ [62]. An alternative approach to the microsimulation method used here would have been to use a health statetransition model, such as Markov chains; future work in our group will entail a comparative assessment of modelling approaches for predicting the clinical relevance of reducing alcohol consumption.

Rather than use simple regression, alcohol consumption was modelled using a two-part model. In the litera-

Predicted Clinical Relevance of Alcohol Reduction ture, two-part models tend to be preferred to linear regression from a statistical perspective when the data consist of a mixture of zero values and continuous positive values. This is because two-part models help to distinguish between using zero as a value in itself and not also as a substitute for negative or missing data $[63,64]$. Furthermore, simple regression is only able to predict positive alcohol consumption, whereas a large proportion of patients do not drink every day. Thus, the present model of alcohol consumption is a more accurate representation of real-life drinking patterns.

The selection of England as the reference country in the model was a result of good quality English data being available for the probabilities of inpatient consultation episodes for each alcohol-attributable disease or injury. These data were used to estimate the baseline risk of each event for the general population. The use of FCE data may have led to overestimation of the number of inpatient alcohol-attributable diseases or injuries, as patients may be hospitalised more than once during a single year for the same problem, or be transferred from the care of one consultant to another for specialist treatment or diagnosis. However, the objective of the model was to estimate the number of alcohol-attributable events necessitating hospitalisation, not the number of patients with alcohol-attributable events.

While the model was developed with England as the reference case, the nalmefene clinical trial data used to model alcohol consumption also included patients from other European countries. This could have introduced bias in the model since patterns of drinking can vary between countries [7]. Drinking patterns in England are considered to feature a higher number of intermittent episodes of heavy drinking compared with some other European countries where more constant levels of moderate drinking are seen [16]. Therefore, it is likely that, relative to the English setting, the model results may have underestimated the incidence of events influenced by short-term heavy drinking, such as ischaemic stroke, and overestimated the incidence of events that are more dependent on continuous alcohol consumption over time. On the other hand, use of alcohol consumption data from European-wide clinical trials and the development of risk algorithms based on systematic literature reviews, including international literature, may, to some extent, allow the model results to be generalised to a pan-European or even global context.

While the model took into account the relative risk of different events over different clinically relevant time periods (1 day, 1 or 6 months), it did not take into account the conditional probabilities of events based on previous 
occurrence of the same or other diseases. The relationship between alcohol consumption and the probability of injury was also simplified; blood alcohol concentration, which depends not only on how much a person drinks but also on the duration of time over which alcohol is consumed, is known to be a better predictor of the probability of an accident during a drinking day than the total amount of alcohol consumed that day. In order to compensate for this limitation, the increased risk of injuries associated with drinking was assumed to apply over a period of $3 \mathrm{~h}$ per drinking day within the base case. This approach has previously been used in other studies assessing the risk of accidents associated with alcohol consumption $[11,50]$.

Despite the limitations of the model discussed, it is likely that the results reported are conservative and may underestimate the beneficial impact of reducing alcohol consumption. For example, while an extensive list of conditions has been established as alcohol attributable [65], not all could be considered in the model due to the time horizon of the analysis and the availability of data. The alcohol-attributable events selected for inclusion in the model were those with a strong published evidence base demonstrating an association between alcohol consumption and risk, and those shown to have a high incidence of hospitalisation over a 1-year time horizon in the population of alcohol-dependent patients modelled and for which nalmefene is licensed. Thus, even though there is a strong relationship between alcohol consumption and, for example, cancer $[66,67]$, these risks were not modelled as there is a longer time lag between alcohol consumption and cancer incidence than that considered in the nalmefene clinical trials. Furthermore, as 'events' were defined as inpatient hospitalisation episodes, it should be noted that the model does not account for the full burden of $\mathrm{AD}$, as any cases of alcohol-attributable injury or disease not warranting hospitalisation were ignored. It should finally be noted that the model did not take into account the social burden of alcohol misuse; as the cost of criminal justice associated with alcohol misuse is estimated to represent almost a quarter of public sector resource costs in the UK [68], this would be expected to present an added benefit of reducing alcohol consumption.

The model had good internal and external validity, making use of risk equations that have previously been used and validated in estimating the burden of alcohol abuse in terms of disability-adjusted life years and mortality in various regions of the world $[11,13,16,35]$. The external validation demonstrated that the model outputs (number of inpatient consultation events) were closely aligned with existing published evidence. A simple calculation, based on a single alcohol-attributable relative risk for each event and an alternative source of data for the number of events in the general population (WHOHMDB), supported the magnitude of the outcomes of the risk equations used in the model. The validation process was subject to a number of limitations, including the fact that the national statistics referenced for the model through the HES database included only events reported in England, whereas for the external validation WHO$\mathrm{HMDB}$ data could only be obtained for the UK as a whole. In addition, a correction of the ratio of HES FCE (used in the baseline model) to the 'admissions' variable (used in the external validation) had to be applied to allow a comparison between the baseline model risk and baseline WHO-HMDB risk. As the objective of the external validation exercise was to allow a rough comparison with published data, these limitations were deemed acceptable.

This study demonstrates that the number of alcoholattributable diseases and injuries increases with TAC and the number of HDDs per time period, indicating that harm reduction by reducing alcohol consumption is a valid treatment goal for alcohol-dependent patients. Harm reduction has the added benefit of potentially appealing to patients who may otherwise have been unwilling to commit to treatment that is essential from both a societal and public health perspective. Increasing the provision of treatments for $\mathrm{AD}$, including those designed to support harm reduction, may therefore have profound implications for clinical health burden at the individual and European level [6]. However, it should be remembered that this model used pre-treatment alcohol consumption data. While this approach was deemed appropriate for assessing the health consequences of reducing alcohol consumption in the nalmefene marketing authorisation by the EMA Scientific Advisory Group [39], contextualising the clinical relevance of alcohol reduction using the nalmefene clinical trial results relies on the assumption that patients' drinking patterns during the runin period were representative of longer-term drinking patterns. While the model run-in period was limited to using 2 weeks of data from the nalmefene clinical trials, this provided data for 11,536 patient days, including 9,888 drinking days, which carried sufficient statistical power for the statistical analysis in itself. Nevertheless, this use of short-term data to model longer-term drinking behaviour represents a limitation of the analysis, and results should only be used as a proxy to evaluate the clini- 
cal relevance of alcohol reduction that could be anticipated with nalmefene. The best way to ascertain the clinical relevance of reducing alcohol consumption with nalmefene would be to reproduce the patterns of drinking observed during the clinical trials, an analysis currently being undertaken by our group.

This novel microsimulation modelling approach has made it possible to translate reductions in alcohol consumption in alcohol-dependent patients into harm reduction in terms of alcohol-attributable events avoided. The results of this model could be considered the best possible estimation of the changes in risk associated with variation in alcohol consumption levels, and the potential benefits to be gained by supporting alcohol-dependent patients in reducing their alcohol consumption effectively.

\section{Disclosure Statement}

C.F., P.L., N.R., Y.C. and S.B. are employees of Lundbeck. S.A. and A.M. are employees of Creativ-Ceutical, who were contracted by Lundbeck to support the study. J.R. received an honorarium from Lundbeck for his participation in the study.

\section{References}

1 Edwards G, Gross MM: Alcohol dependence: provisional description of a clinical syndrome. Br Med J 1976;1:1058.

-2 Schuckit MA: Alcohol-use disorders. Lancet 2009;373:492-501.

3 World Health Organisation: International Classification of Diseases and Related Health Problems, 10th revision. Geneva, World Health Organisation, 2007.

4 American Psychiatric Association: Diagnostic and Statistical Manual of Mental Disorders, ed 4, text revision. Washington, American Psychiatric Association, 2000.

5 Wittchen HU, Jacobi F, Rehm J, Gustavsson A, Svensson M, Jönsson B, Olesen J, Allgulander C, Alonso J, Faravelli C, Fratiglioni L, Jennum P, Lieb R, Maercker A, van Os J, Preisig M, Salvador-Carulla L, Simon R, Steinhausen HC: The size and burden of mental disorders and other disorders of the brain in Europe 2010. Eur Neuropsychopharmacol 2011;21:655-679.

-6 Rehm J, Shield K, Rehm M, Gmel G, Frick U: Modeling the impact of alcohol dependence on mortality burden and the effect of available treatment interventions in the European Union. Eur Neuropsychopharmacol 2012;23: 89-97.

7 Shield K, Kehoe T, Gmel G, Rehm M, Rehm J: Societal Burden of Alcohol. Copenhagen, WHO Regional Office for Europe, 2012.

$>8$ Nutt DJ, King LA, Phillips LD: Drug harms in the UK: a multicriteria decision analysis. Lancet 2010;376:1558-1565.

9 Rehm J, Zatonksi W, Taylor B, Anderson P: Epidemiology and alcohol policy in Europe. Addiction 2011;106:11-19.

10 Roerecke M, Rehm J: Alcohol use disorders and mortality: a systematic review and metaanalysis. Addiction 2013;108:1562-1578.

11 Rehm J, Mathers C, Popova S, Thavorncharoensap $\mathrm{M}$, Teerawattananon $\mathrm{Y}$, Patra J: Global burden of disease and injury and economic cost attributable to alcohol use and alcohol-use disorders. Lancet 2009;373:22232233.
12 World Health Organisation: Global Health Risks: Mortality and Burden of Disease Attributable to Selected Major Risks. Geneva, World Health Organisation, 2009.

13 Lim SS, Vos T, Flaxman AD, Danaei G, Shibuya K, Adair-Rohani H, Amann M, Anderson HR, Andrews KG, Aryee M, et al: A comparative risk assessment of burden of disease and injury attributable to 67 risk factors and risk factor clusters in 21 regions, 19902010: a systematic analysis for the Global Burden of Disease Study 2010. Lancet 2013;380: 2224-2260.

14 Rehm J, Baliunas D, Borges GLG, Graham K, Irving H, Kehoe T, Parry CD, Patra J, Popova S, Poznyak V: The relation between different dimensions of alcohol consumption and burden of disease: an overview. Addiction 2010; 105:817-843.

15 Rehm J, Room R, Graham K, Monteiro M, Gmel G, Sempos CT: The relationship of average volume of alcohol consumption and patterns of drinking to burden of disease: an overview. Addiction 2003;98:1209-1228.

16 Rehm J, Shield KD, Rehm MX, Gmel G, Frick U: Alcohol Consumption, Alcohol Dependence and Attributable Burden of Disease in Europe: Potential Gains from Effective Interventions for Alcohol Dependence. Toronto, Centre for Addiction and Mental Health, 2012.

17 Hemström Ö, Leifman H, Ramstedt M: The ECAS survey on drinking patterns and alcohol-related problems; in Norström T (ed): Alcohol in Postwar Europe: Consumption, Drinking Patterns, Consequences and Policy Responses in 15 European Countries. Stockholm, National Institute of Public Health, 2002.

18 Anderson P, Baumberg B: Alcohol in Europe. London, Institute of Alcohol Studies, 2006.

19 European Medicines Agency: Guideline on the Development of Medicinal Products for the Treatment of Alcohol Dependence. London, Committee for Medicinal Products for Human Use, 2010.
20 World Health Organisation: International Guide for Monitoring Alcohol Consumption and Related Harm. Geneva, World Health Organisation, 2000.

21 Barbosa C, Taylor B, Godfrey C, Rehm J, Parrott S, Drummond C: Modelling lifetime QALYs and health care costs from different drinking patterns over time: a Markov model. Int J Methods Psychiatr Res 2010;19:97-109.

22 Mohapatra S, Patra J, Popova S, Duhig A, Rehm J: Social cost of heavy drinking and alcohol dependence in high-income countries. Int J Public Health 2010;55:149-157.

23 European Medicines Agency: Selincro: Annex I: Summary of Product Characterisics. London, European Medicines Agency, 2013.

24 van den Brink W, Sorensen P, Torup L, Gual A: Long-term efficacy, tolerability, and safety of nalmefene as-needed in alcohol-dependence: a randomised, double-blind, placebocontrolled study. Alcohol Clin Exp Res 2012; 36:247A.

25 van den Brink W, Sorensen P, Mann K, Gual A: Long-term efficacy of nalmefene as-needed in alcohol-dependent patients with high drinking risk levels: results of a subgroup analysis. Presented at 21st European Congress of Psychiatry, Nice, 2013.

26 Gual A, He Y, Torup L, van den Brink W, Mann K: ESENSE 2: a randomised, doubleblind, placebo-controlled study of nalmefene, as-needed use in alcohol-dependent patients. Alcohol Clin Exp Res 2012;36:246A.

27 Mann K, Bladström A, Torup L, Gual A, van den Brink W: Extending the treatment options in alcohol dependence: a randomized controlled study of as-needed nalmefene. Biol Psychiatry 2013;73:706-713.

28 van den Brink W, Aubin H-J, Bladström A, Torup L, Gual A, Mann K: Efficacy of asneeded nalmefene in alcohol-dependent patients with at least a high drinking risk level: results from a subgroup analysis of two randomized controlled 6-month studies. Alcohol Alcohol 2013;48:746. 
29 Leon DA, Chenet L, Shkolnikov VM, Zakharov S, Shapiro J, Rakhmanova G, Vassin S, McKee M: Huge variation in Russian mortality rates 1984-94: artefact, alcohol, or what? Lancet 1997;350:383.

- 30 Skog OJ: Alcohol and suicide in Denmark, 1911-24: experiences from a 'natural experiment'. Addiction 1993;88:1189-1193.

-31 Dills AK, Miron JA: Alcohol prohibition and cirrhosis. Am Law Econ Rev 2004;6:285-318.

32 Her M, Rehm J: Alcohol and all-cause mortality in Europe 1982-1990: a pooled cross-section time-series analysis. Addiction 1998;93: 1335-1340.

-33 Norström T: Per capita alcohol consumption and all-cause mortality in 14 European countries. Addiction 2002;96:113-128.

-34 Rehm J, Roerecke M: Reduction of drinking in problem drinkers and all-cause mortality. Alcohol Alcohol 2013;48:509-513.

35 Rehm J, Room R, Monteiro M, Gmel G, Graham K, Rehn N, Sempos CT, Frick U, Jernigan D: Alcohol use; in Ezzati M, Lopez AD, Rodgers A, Murray CJL (eds): Comparative Quantification of Health Risks: Global and Regional Burden of Disease Attributable to Selected Major Risk Factors. Geneva, World Health Organisation, 2004, vol 1.

36 McPherson K, Marsh T, Brown M, Britain G: Foresight: Tackling Obesities: Future Choices: Modelling Future Trends in Obesity and the Impact on Health. London, Government Office for Science, 2007.

-37 Rutter CM, Zaslavsky AM, Feuer EJ: Dynamic microsimulation models for health outcomes - a review. Med Decis Making 2011;31: $10-18$.

38 Will B, Berthelot J-M, Nobrega K, Flanagan W, Evans W: Canada's population health model (POHEM): a tool for performing economic evaluations of cancer control interventions. Eur J Cancer 2001;37:1797-1804.

39 European Medicines Agency: European Public Assessment Report for Selincro. London, Committee for Medicinal Products for $\mathrm{Hu}$ man Use (CHMP), 2012.

40 Horton N, Kim E, Saitz R: A cautionary note regarding count models of alcohol consumption in randomized controlled trials. BMC Med Res Methodol 2007;7:9.

41 World Health Organisation: The Global Burden of Disease: 2004 Update. Geneva, Department of Health Statistics and Informatics, Information, Evidence and Research Cluster, 2008.

42 Rehm J, Room R, Taylor B: Method for moderation: measuring lifetime risk of alcoholattributable mortality as a basis for drinking guidelines. Int $\mathrm{J}$ Methods Psychiatric Res 2008; 17:141-151.
43 Roerecke M, Rehm J: Irregular heavy drinking occasions and risk of ischemic heart disease: a systematic review and meta-analysis. Am J Epidemiol 2010;171:633-644.

-44 Gerlich M, Krämer A, Gmel G, Maggiorini M, Lüscher T, Rickli H, Kleger G, Rehm J: Patterns of alcohol consumption and acute myocardial infarction: a case-crossover analysis. Eur Addict Res 2009;15:143-149.

45 Patra J, Taylor B, Irving H, Roerecke M, Baliunas D, Mohapatra S, Rehm J: Alcohol consumption and the risk of morbidity and mortality for different stroke types: a systematic review and meta-analysis. BMC Public Health 2010;10:258.

46 Guiraud V, Amor MB, Mas J-L, Touzé E: Triggers of ischemic stroke a systematic review. Stroke 2010;41:2669-2677.

47 Rehm J, Taylor B, Mohapatra S, Irving H, Baliunas D, Patra J, Roerecke M: Alcohol as a risk factor for liver cirrhosis: a systematic review and meta-analysis. Drug Alcohol Rev 2010;29:437-445.

48 Irving HM, Samokhvalov AV, Rehm J: Alcohol as a risk factor for pancreatitis: a systematic review and meta-analysis. JOP 2009;10: 387.

49 Samokhvalov A, Irving H, Rehm J: Alcohol consumption as a risk factor for pneumonia: a systematic review and meta-analysis. Epidemiol Infect 2010;138:1789-1795.

50 Rehm J, Scafato E: Indicators of alcohol consumption and attributable harm for monitoring and surveillance in European Union countries. Addiction 2011;106:4-10.

51 Taylor B, Shield K, Rehm J: Combining best evidence: a novel method to calculate the alcohol-attributable fraction and its variance for injury mortality. BMC Public Health 2011; 11:265.

52 Scilab Enterprises: Scilab: free and open source software for numerical computation (OS, version 5.3.3). http://www.scilab.org/.

53 Breslow NE, Clayton DG: Approximate inference in generalized linear mixed models. J Am Stat Assoc 1993;88:9-25.

54 Dean C, Nielsen JD: Generalized linear mixed models: a review and some extensions. Lifetime Data Anal 2007;13:497-512.

55 Akaike H: Information theory and an extension of the maximum likelihood principle; in Petrov BN, Caski F: Second International Symposium on Information Theory. Budapest, Akademiai Kiado, 1973.

56 Health and Social Care Information Centre: Hospital episode statistics online. www. hesonline.nhs.uk/Ease/servlet/Content Server?siteID=1937 (accessed April 23, 2013).

57 Taylor B, Irving H, Kanteres F, Room R, Borges G, Cherpitel C, Greenfield T, Rehm J: The more you drink, the harder you fall: a systematic review and meta-analysis of how acute alcohol consumption and injury or collision risk increase together. Drug Alcohol Depend 2010;110:108-116.
58 Roerecke M, Rehm J: The cardioprotective association of average alcohol consumption and ischaemic heart disease: a systematic review and meta-analysis. Addiction 2012;107:12461260.

59 World Health Organisation: European hospital morbidity database. http://data.euro. who.int/hmdb/index.php (accessed April 19, 2013).

60 McQueen J, Howe TE, Allan L, Mains D, Hardy V: Brief interventions for heavy alcohol users admitted to general hospital wards. Cochrane Database Syst Rev 2011;8:CD005191.

61 Roerecke M, Gual T, Rehm J: Reduction of alcohol consumption and subsequent mortality in alcohol use disorders: systematic review and meta-analyses. J Clin Psychiatry 2013; 74:e1181-e1189.

62 OECD: Tackling Harmful Alcohol Use: The Health and Economic Impact of Prevention Policies, DELSA/HEA/EP(2012)2. Paris, Directorate for Employment, Labour and Social Affairs, Health Committee, 2012.

63 Duan N, Manning WG, Morris CN, Newhouse JP: A comparison of alternative models for the demand for medical care. J Bus Econ Stat 1983;1:115-126.

64 Olsen MK, Schafer JL: A two-part randomeffects model for semicontinuous longitudinal data. J Am Stat Assoc 2001;96:730-745.

- 65 Rehm J, Monteiro M, Room R, Gmel G, Jernigan D, Frick U, Graham K: Steps towards constructing a global comparative risk analysis for alcohol consumption: determining indicators and empirical weights for patterns of drinking, deciding about theoretical minimum, and dealing with different consequences. Eur Addict Res 2001;7:138-147.

66 International Agency for Research on Cancer: Alcohol Consumption and Ethyl Carbamate: Monograph 96 on the Evaluation of Carcinogenic Risks to Humans. Lyon, World Health Organisation International Agency for Research on Cancer, 2010.

67 Schütze M, Boeing H, Pischon T, Rehm J, Kehoe T, Gmel G, Olsen A, Tjønneland AM, Dahm CC, Overvad K: Alcohol attributable burden of incidence of cancer in eight European countries based on results from prospective cohort study. Br Med J 2011;342.

68 Godfrey C: Cost effectiveness of treatment for alcohol problems: findings of the randomised UK alcohol treatment trial (UKATT). Br Med J 2005;331:544-548.

69 Reynolds K, Lewis LB, Nolen JDL, Kinney GL, Sathya B, He J: Alcohol consumption and risk of stroke. JAMA 2003;289:579-588.

70 Corrao G, Bagnardi V, Zambon A, Arico S: Exploring the dose-response relationship between alcohol consumption and the risk of several alcohol-related conditions: a metaanalysis. Addiction 1999;94:1551-1573. 